\title{
FATIGUE FRACTURE SURFACE ANALYSIS IN C45 STEEL SPECIMENS USING X-RAY FRACTOGRAPHY
}

\author{
K. RAJANNA, $\nmid \ddagger$ B. H. KOLSTER $\ddagger$ and B. PATHIRAJ $\S$ \\ †Materials Science Section, Faculty of Mechanical Engineering, University of Twente, \\ 7500 AE Enschede, The Netherlands \\ $\S$ Foundation for Advanced Metals Science (SGM), 7550 KA Hengelo, \\ The Netherlands
}

\begin{abstract}
X-Ray fractography is a useful technique to analyse the mechanisms operating in fracture and involves an examination of the fracture surface. In the present investigation, this technique has been employed to study the fatigue fracture behaviour of a medium carbon steel of C45 grade in different heat treated conditions. The different trends observed in the residual stress $\left(\sigma_{\mathrm{r}}\right)$ and diffraction profile full width at half maximum intensity $(B)$ relationships with the maximum stress intensity factor $\left(K_{\max }\right)$ on the fracture surface have been correlated to the differences in flow characteristics of these materials. The root mean square value of microstrain $\epsilon$, and the coherent domain (particle) size, $D$, were determined through single line diffraction profile (Voigt's) analysis. It has been observed that contribution of microstrain to profile broadening is more significant than that due to domain size. However, at higher $K_{\max }$ values an influence of $D$ was found on line broadening, to a small extent. Results of sub-surface stress measurements were compared in two conditions. A good correlation was noticed between the depths below the fracture surface, designated as $y_{\max }$, at which the measured $\sigma_{\mathrm{r}}$ reaches the base material value and the corresponding monotonic plastic zone size $\left(r_{p}\right)$ obtained by calculation. The observed depths below the fracture surface $\left(y_{\text {peak }}\right)$ at which an increase in $\sigma_{\mathrm{r}}$ or a decrease in $B$ was noticed, appear to be related to the conditions of the near-tip regions where the material has undergone severe fatigue damage and cyclic softening.
\end{abstract}

\section{INTRODUCTION}

DuRING the last few years much research has been oriented towards analysing the causes and mechanisms operating during fracture through the $\mathrm{X}$-ray fractographic technique. The technique has been applied on specimens tested for fracture toughness[1,2], stress corrosion cracking[3] and fatigue crack growth[4-6] as well as in cases involving components that failed in service[7-9].

The method involves $\mathrm{X}$-ray stress analysis of the fracture surface at different locations corresponding to different crack lengths, $a$, and maximum stress intensity factors, $K_{\max }$. The residual stress, $\sigma_{\mathrm{r}}$, and full width at half maximum, $B$, of the diffraction profile are correlated to fracture mechanics parameters such as maximum stress intensity factor $K_{\max }$ and stress intensity range $\Delta K$. In the literature, different types of distributions relating $\sigma_{\mathrm{r}}$ to, $a$ (or $\Delta K$ or $K_{\max }$ ), have been reported. They include either a monotonic increase[10], a monotonic decrease[11] or an increase to a maximum followed by a decrease[4,12]. In addition, the monotonic plastic zone size $\left(r_{\mathrm{p}}\right)$ could be estimated from the sub-surface X-ray stress measurements after successive removal of layers. During these measurements, an increase in residual stress has been observed just below the fracture surface by several workers. Though such an increase has been attributed to surface roughness $[4,6]$ or crack closure $[4,13]$ or cyclic plastic zone[8] effects, an unequivocal explanation is still not available.

In this investigation the fatigue behaviour of a $\mathrm{C} 45$ carbon steel in different heat treated conditions were studied. Through surface and sub-surface stress measurements, the variation in the $\sigma_{\mathrm{r}}-K_{\max }$ and $B-K_{\max }$ relationships were investigated.

The single line profile (Voigt's) analysis according to Mittemeijer's method was employed to evaluate the microstrain $\epsilon$ and the coherent domain size $D$. The relative contribution of these two on line broadening are also discussed.

Ton study leave from Corporate R \& D Division, Hyderabad, India. 


\section{EXPERIMENTAL PROCEDURE}

\subsection{Heat treatment and specimen preparation details}

A hot rolled medium carbon steel of $\mathrm{C} 45$ grade was selected for this investigation. Its chemical composition is shown in Table 1 . Blanks with dimensions $(80 \mathrm{~mm} \times 75 \mathrm{~mm} \times 15 \mathrm{~mm})$ were cut from the stock material and were solutionised at $850^{\circ} \mathrm{C}$ for $1 \mathrm{~h}$ and subsequently water quenched. Thereafter a few of them were subjected to tempering treatments at 200,400 and $600^{\circ} \mathrm{C}$ and a stress relief anneal treatment at $720^{\circ} \mathrm{C}$. In all cases the duration was $2 \mathrm{~h}$. In the discussions that follow, the steel in the quenched, 200,400 and $600^{\circ} \mathrm{C}$ tempered and $720^{\circ} \mathrm{C}$ annealed states will be referred to as conditions $1,2,3,4$ and 5 respectively. The room temperature mechanical properties of the material in these conditions are given in Table 2. It is interesting to note that the strength was higher when tempered at $400^{\circ} \mathrm{C}$. Similar observations have been seen by others in case of plain carbon steels[14]. In conditions 1 and 2, it was found that the hardness varied from $560 \mathrm{VHN}$ at the surface to about $430 \mathrm{VHN}$ in the interior. After the respective heat treatments, compact tension specimens (CTS) were prepared from these blanks as per ASTM E-647 standard for fatigue crack growth tests. Machine notches were made by the spark erosion technique with the notch length in the rolling direction. In each case, the initial crack-depth ratio $(a / W)$ was maintained at about 0.3 .

\subsection{Fatigue crack growth tests}

Fatigue crack growth tests were performed at room temperature $\left(20^{\circ} \mathrm{C}\right)$ on a $100 \mathrm{kN}$ universal static/dynamic MTS servo-hydraulic test system. All tests were carried out according to ASTM E-647 standard and in tension-tension mode under constant amplitude loading. A test frequency of $30 \mathrm{~Hz}$ and a stress ratio $(R)$ of 0.1 were employed.

\section{3. $X$-Ray residual stress measurements}

The residual stress $\sigma_{\mathrm{r}}$ was determined according to the $\sin ^{2} \psi$ method[15] using a Rigaku Strainflex MSF-2M type X-ray stress analyser. Filtered $\mathrm{Cr}-\mathrm{K} \alpha$ radiation and the $\{211\}$ reflection of ferrite were used for the stress measurements. The irradiated area was restricted to a strip of $10 \mathrm{~mm}$ length and $1 \mathrm{~mm}$ width with the aid of a mask whose width coincided with the direction of crack growth. The measurements were performed at different crack locations on the fracture surface which corresponded to different $K_{\max }$ or $\Delta K$ values. The sub-surface stress distribution was determined from measurements after removing layers of material successively by electropolishing. The depth to which the material was removed was determined accurately $( \pm 1 \mu \mathrm{m})$ using a precision type dial gauge and a special setup.

\subsection{Single line profile analysis}

Full width at half maximum, $B$, and the integral breadth, $\beta$, parameters can be used as indicators of strain in a crystal lattice [16]. These require some corrections for instrumental effects in order to obtain true strain values. The actually observed profile shapes can be approximated

Table 1. Actual chemical composition of the $\mathrm{C} 45$ steel (weight \%)

\begin{tabular}{ccccc}
\hline $\mathrm{C}$ & $\mathrm{Mn}$ & $\mathrm{Si}$ & $\mathrm{P}$ & $\mathrm{S}$ \\
\hline 0.44 & 0.64 & 0.23 & $<0.04$ & 0.032 \\
\hline
\end{tabular}

Table 2. Room temperature mechanical properties of the $\mathbf{C} 45$ steel

\begin{tabular}{lcccc}
\hline & $\begin{array}{c}0.2 \% \text { Proof } \\
\text { stress } \\
(\mathrm{MPa})\end{array}$ & $\begin{array}{c}\text { Tensile } \\
\text { stress } \\
(\mathrm{MPa})\end{array}$ & $\begin{array}{c}\text { Elongation } \\
(\%) \\
(\mathrm{GL}=25 \mathrm{~mm})\end{array}$ & $\begin{array}{c}\text { Surface } \\
\text { hardness } \\
(\mathrm{VHN})\end{array}$ \\
\hline Condition & 1020 & 1050 & 6.0 & 560 \\
Condition 1 $\left(850^{\circ} \mathrm{C} / \mathrm{WQ}\right)$ & 920 & 965 & 8.4 & 520 \\
Condition 2 (WQ \& $200^{\circ} \mathrm{C}$ temper) & 1150 & 1220 & 10.6 & 340 \\
Condition 3 (WQ \& $400^{\circ} \mathrm{C}$ temper) & 630 & 720 & 18.0 & 230 \\
Condition 5 (WQ \& $700^{\circ} \mathrm{C}$ temper) & 308 & 565 & 28.0 & 167 \\
\hline
\end{tabular}


to a Voigt's function which is a convolution of the Cauchy and Gaussian functions[17, 18]. The breadths of the Cauchy and Gaussian components can be obtained from the ratio of $B$ and $\beta[19]$.

It should be mentioned that in such analyses, strictly the $\alpha_{2}$ component would have to be eliminated from the measured profiles employing correction procedures according to Rachinger or others or by the use of a monochromator. In the present case such treatments were not adopted as the measurement system employs a parallel beam geometry which causes a broadening effect even in the case of an annealed sample. In a few cases, analyses were performed with and without $\mathrm{K} \alpha_{2}$ correction and the final results were not found to be significantly influenced. Although, in principle the absolute values could differ somewhat, the trends or the relative values noticed are not expected to be seriously affected.

Though this technique is preferably used with multiple orders of a reflection, it has also been used in single line analysis[18]. In the latter case it is assumed that the Cauchy component of the structurally broadened profile, $f$, is solely due to the crystallite size and the Gaussian solely due to strain $[17,18,20]$. The line profile, $h$, measured by the single line method is the convolution of the standard profile, $g$, which is due to instrumental effects and the structurally broadened profile, $f$, which is due to diffraction effects. If $h, g$ and $f$ are assumed to be Voigt functions[18] and subscripts $C$ and $G$ denote Cauchy and Gaussian components of the respective Voigt profile then:

$$
\beta_{c}^{f}=\beta_{c}^{h}-\beta_{c}^{g}
$$

and

$$
\left(\beta_{G}^{f}\right)^{2}=\left(\beta_{G}^{h}\right)^{2}-\left(\beta_{G}^{g}\right)^{2} .
$$

The Cauchy and Gaussian components can be obtained from the $B / \beta$ ratios for the $h$ and $g$ profiles, using the following empirical relations[18]

$$
\beta_{c} / \beta=2.0207-0.4803(B / \beta)-1.7756(B / \beta)^{2}
$$

and

$$
\beta_{G} / \beta=0.6420+1.4187(B / \beta-2 / \pi)^{0.5}-2.2043(B / \beta)+1.8706(B / \beta)^{2}
$$

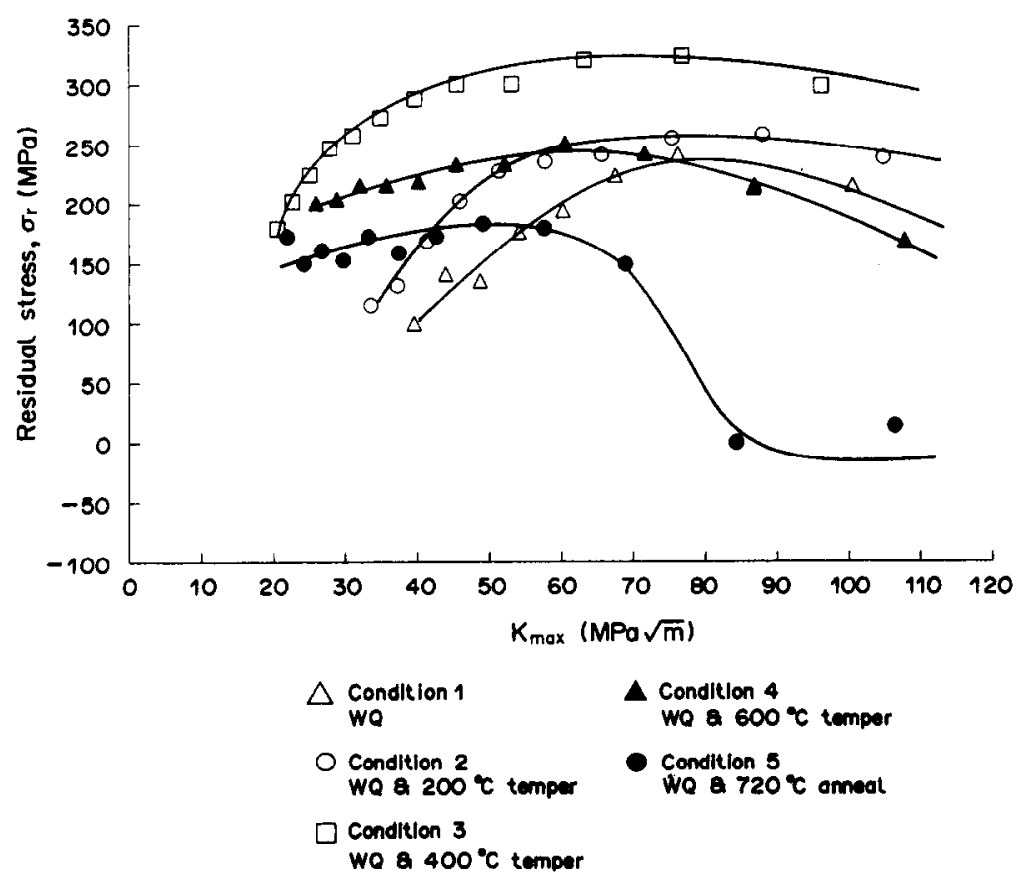

Fig. 1. Residual stress, $\sigma_{r}$, distribution as a function of $K_{\max }$ on the fracture surface of $\mathrm{C} 45$ steel. 
Then the coherent domain size, $D$, is given by

$$
D=\frac{\lambda}{\beta_{c}^{f} \cos \theta}
$$

and the microstrain, $\epsilon$, is given by

$$
\epsilon=\frac{\beta_{G}^{f}}{4 \tan \theta}
$$

where $\lambda$ is the wave length of the $\mathrm{X}$-ray radiation used and $\theta$ is the Bragg angle.

\section{RESULTS AND DISCUSSIONS}

\subsection{X-Ray analysis of the fatigue fracture surface}

The distributions of residual stress $\sigma_{\mathrm{r}}$ as well as the full width at half maximum, $B$, of the diffraction profile (at $\psi=0^{\circ}$ ), as a function of $K_{\max }$ measured on the fracture surface of specimens in different heat treated conditions are shown in Figs 1 and 2, respectively. In all cases, the $\sigma_{\mathrm{r}}$ values were found to be tensile in nature. They exhibited increasing trends in the fatigue region and decreasing trends in the fast fracture region with $K_{\max }$ (Fig. 1). In each condition, the $K_{\max }$ value at which $\sigma_{\mathrm{r}}$ was a maximum coincided with the onset of fast fracture identified from the roughness differences in the fracture surface or from the fatigue crack growth rate results. The material in condition $3\left(400^{\circ} \mathrm{C}\right.$ temper $)$ has shown the maximum stress at any $K_{\max }$ value as compared to other conditions. The observed maximum stress was about $325 \mathrm{MPa}$. Probably this condition refers to a best combination of ductility and toughness. In conditions 1,2 and 4 the $\sigma_{\mathrm{r}}$ was found to increase up to $250 \mathrm{MPa}$ in the fatigue region. In case of condition 5 (annealed), $\sigma_{\mathrm{r}}$ was found to show an initial small increase in the fatigue region followed by a sharp decrease to levels almost equal to $0 \mathrm{MPa}$ beyond a $K_{\max }$ value of $70 \mathrm{MPa} \sqrt{\mathrm{m}}$. The rate of increase of $\sigma_{\mathrm{r}}$ was higher for conditions 1,2 and 3 than for conditions 4 and 5 (Fig. 1).

A different trend was noticed in case of full width at half maximum, $B$, variations. Figure 2 shows the $B$ variations with $K_{\max }$ obtained on the same specimens. The rate of increase in the lower $K_{\max }$ range is higher for cases 4 and 5 than for 1,2 and 3.

An attempt was made to analyse the relative contribution of the microstrain and the coherent domain size components on the observed line broadening. The microstrain $\epsilon$ and coherent domain size $D$ values were determincd using eqs (4) and (5)[18]. $\beta_{C}$ and $\beta_{G}$ components for the standard profile $g$ were determined using $B / \beta$ ratio of the material in condition 5 (annealed). The variations

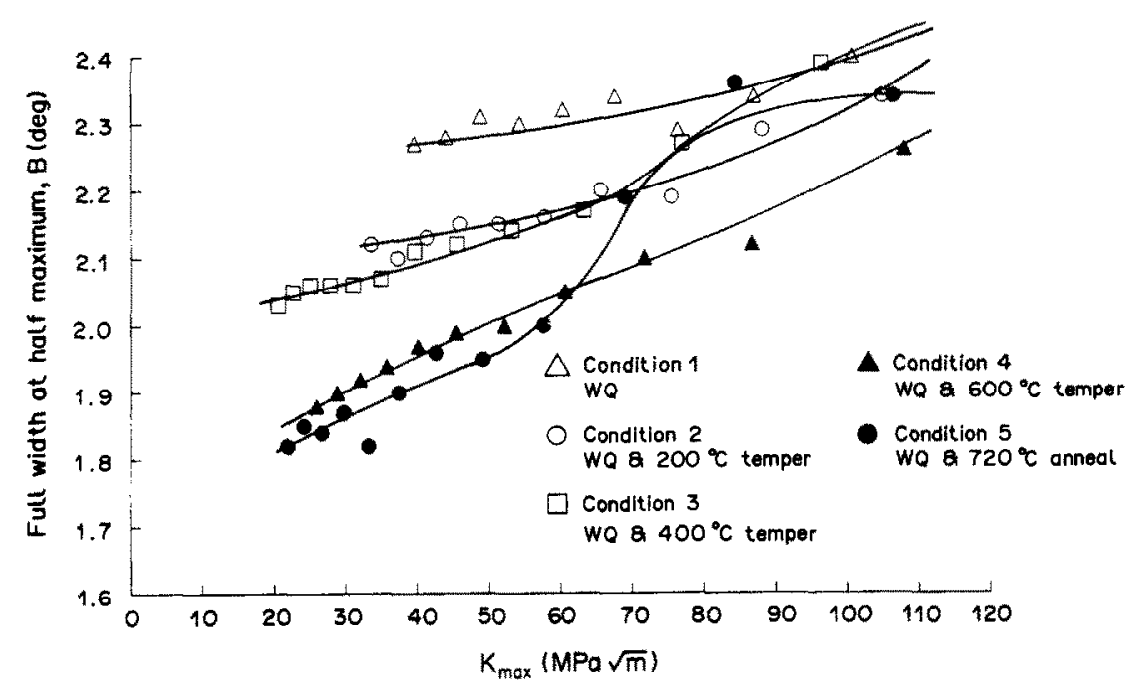

Fig. 2. Full width at half maximum, $B$, distribution as a function of $K_{\max }$ on the fracture surface of $C 45$ steel. 


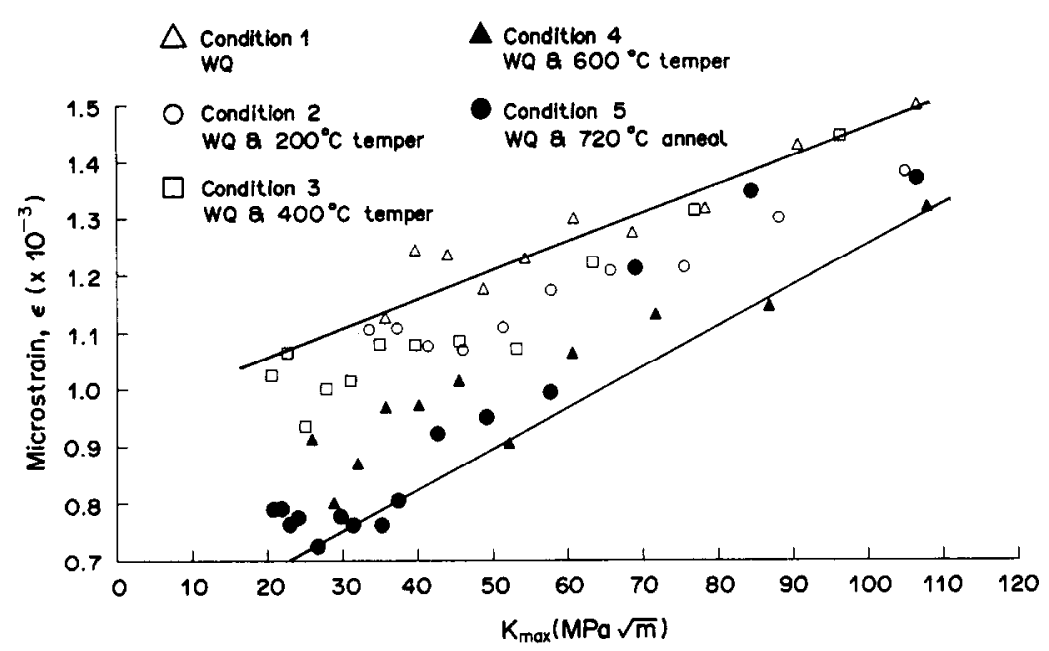

Fig. 3. Micro strain, $\epsilon$, variation on the fracture surface as a function of $K_{\max }$.

of $\epsilon$ and $D$ with $K_{\max }$ for different conditions are shown in Figs 3 and 4 respectively. The microstrain appear to play a predominant role in broadening. Though $D$ values were found to be rather high (more than about $1500 \AA$ ) at lower $K_{\max }$ values they were found to decrease with increasing $K_{\max }$ values (Fig. 4). A minimum value of about $800 \AA$ was noticed for the material in condition 1 (as quenched). On the other hand, the microstrains were found to show relatively stronger effects. At lower $K_{\max }$ values the magnitude was found to be about $1.25 \times 10^{-3}$ for condition 1 and $0.75 \times 10^{-3}$ for condition 5 . While for condition 1 it did not increase much with $K_{\max }$, a sharp increase was noticed for condition 5 beyond a $K_{\max }$ value of about $40 \mathrm{MPa} \sqrt{\mathrm{m}}$. The increase in microstrain with increasing $K_{\max }$ in case of condition 5 was observed to be almost $100 \%$ $\left(0.7 \times 10^{-3}-1.4 \times 10^{-3}\right)$, while the increase in $B$ was only about $30 \%\left(1.8^{\circ}\right.$ to $\left.2.3^{\circ}\right)$. For all tested material conditions, though the microstrain (Fig. 3) and domain size (Fig. 4) differences are large in the fatigue region, there is a converging tendency seen in the fast fracture region.

These observations seem to indicate that the mechanisms which are responsible for the observed variations in $\sigma_{\mathrm{r}}$ and $B$ with $K_{\max }$ values are different. These two represent the macro and micro residual stress states respectively. The difference between the energy absorbed during plastic zone formation and the energy dissipated in the crack growth process appears to have a control on these mechanisms. It may be presumed that in the fast fracture regions, a relatively larger portion of this absorbed energy could have been spent on grain fragmentation with sharply

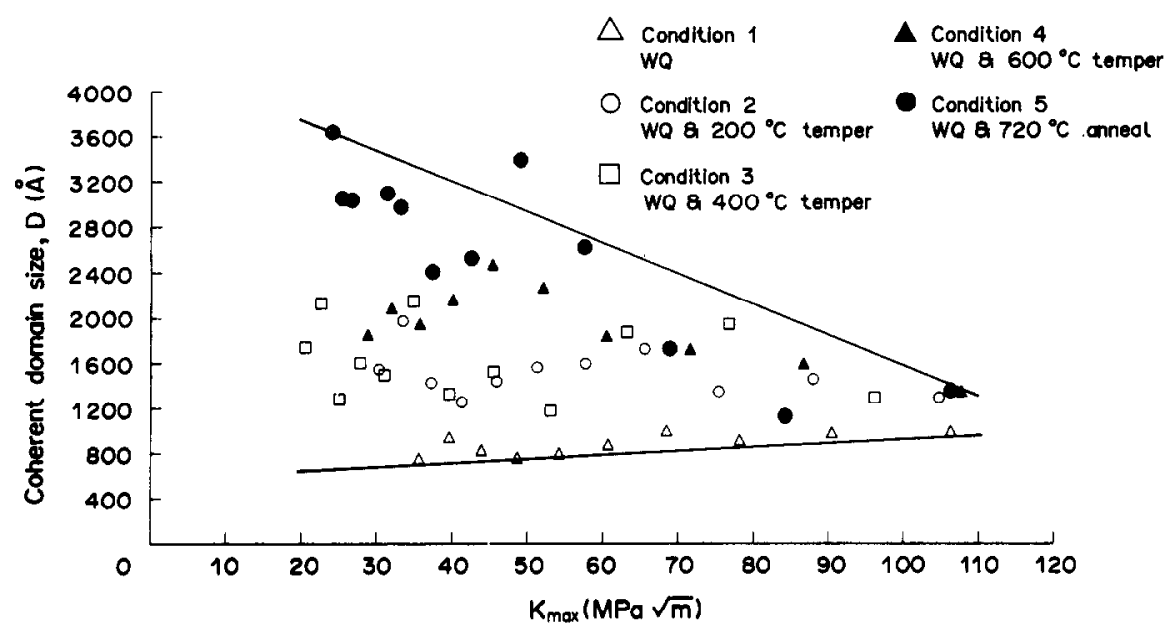

Fig. 4. Coherent domain size, $D$, variation on the fracture surface as a function of $K_{\max }$. 

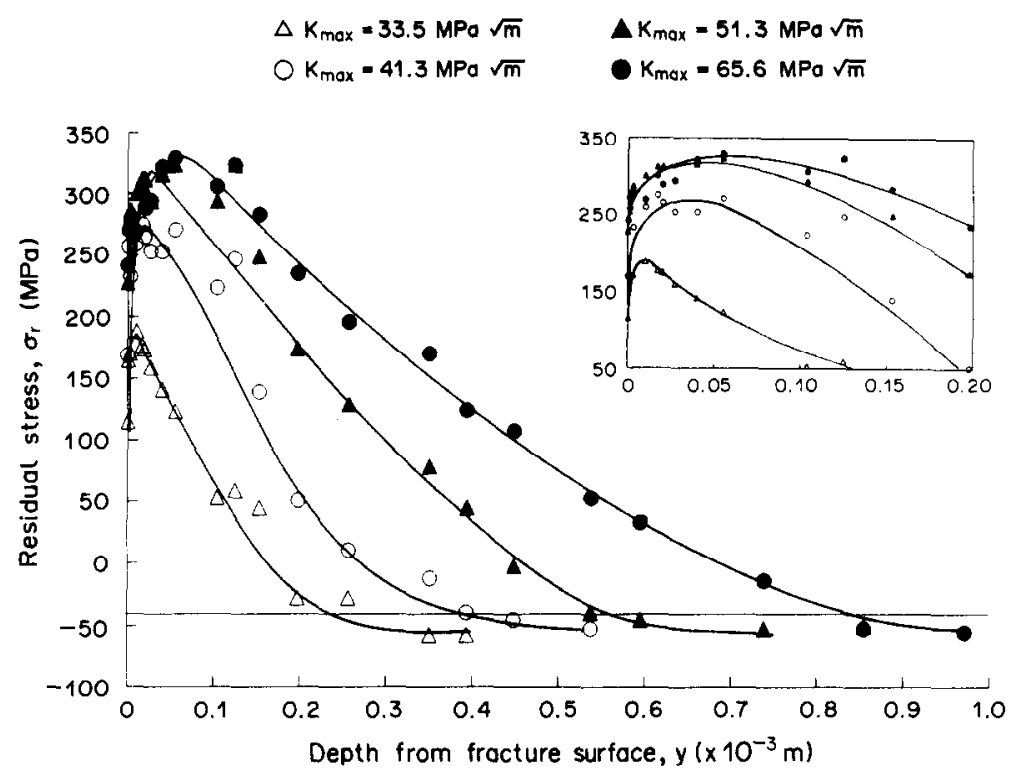

Fig. 5. Residual stress, $\sigma_{r}$, distribution below the fracture surface in condition 2 (WQ \& $200^{\circ} \mathrm{C}$ temper).

increasing microstrains within these fragments. This perhaps is responsible for the relatively small differences seen in the fast fracture regions as compared to the fatigue fracture regions.

\subsection{Sub-surface $X$-ray measurements}

$\mathrm{X}$-ray residual stress measurements below the fracture surface were performed on specimens tested in conditions 2 and 4 . Variation in $\sigma_{\mathrm{r}}$ and $B$ with sub-surface depth (denoted by $y$ ) were examined at different locations corresponding to different $K_{\max }$ values. Figures 5 and 6 show the typical $\sigma_{\mathrm{r}}$ variation with $y$ for conditions 2 and 4 respectively for a few representative $K_{\max }$ levels. The insert figures are enlargements of initial stages.

The residual stresses were found to increase up to a certain depth below the fracture surface (inserts of Figs 5 and 6), followed by a gradual decrease thereafter. At larger depths $\sigma_{\mathrm{r}}$ approached a minimum value of about $-50 \mathrm{MPa}$ and $-5 \mathrm{MPa}$ in conditions 2 and 4 respectively. These observed minimum $\sigma_{\mathrm{r}}$ values were found to correspond well to those measured on samples subjected to similar heat treatments but not subjected to any fatigue tests (about $-40 \mathrm{MPa}$ and $-5 \mathrm{MPa}$ for conditions 2 and 4 respectively). The depth from surface at which the $\sigma_{\mathrm{r}}$ reaches a maximum

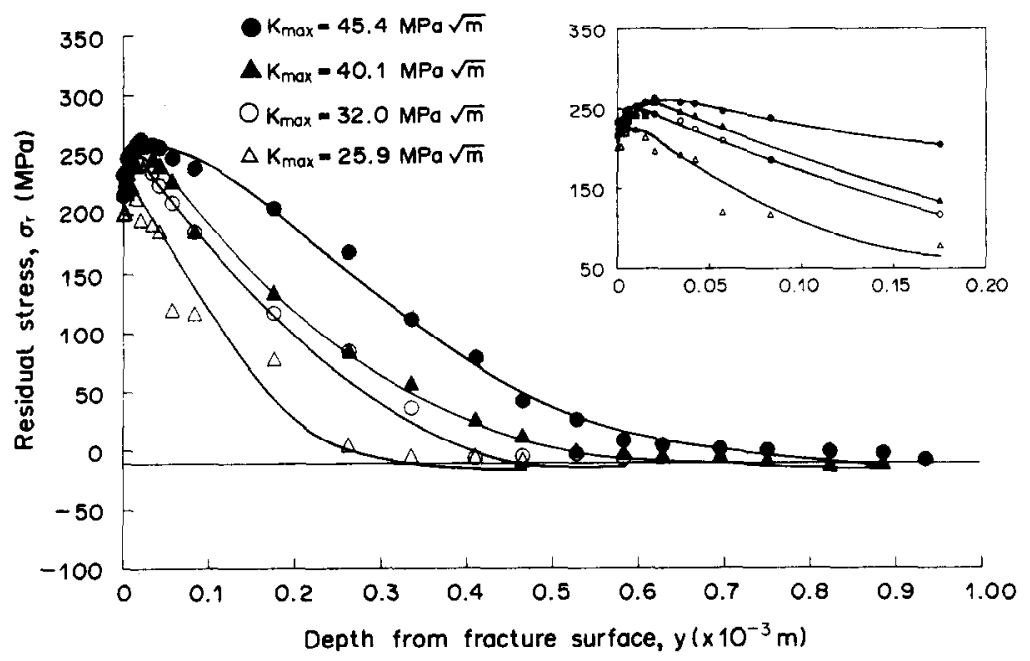

Fig. 6. Residual stress, $\sigma_{\mathrm{r}}$, distribution below the fracture surface in condition 4 (WQ \& $600 \mathrm{C}$ temper). 


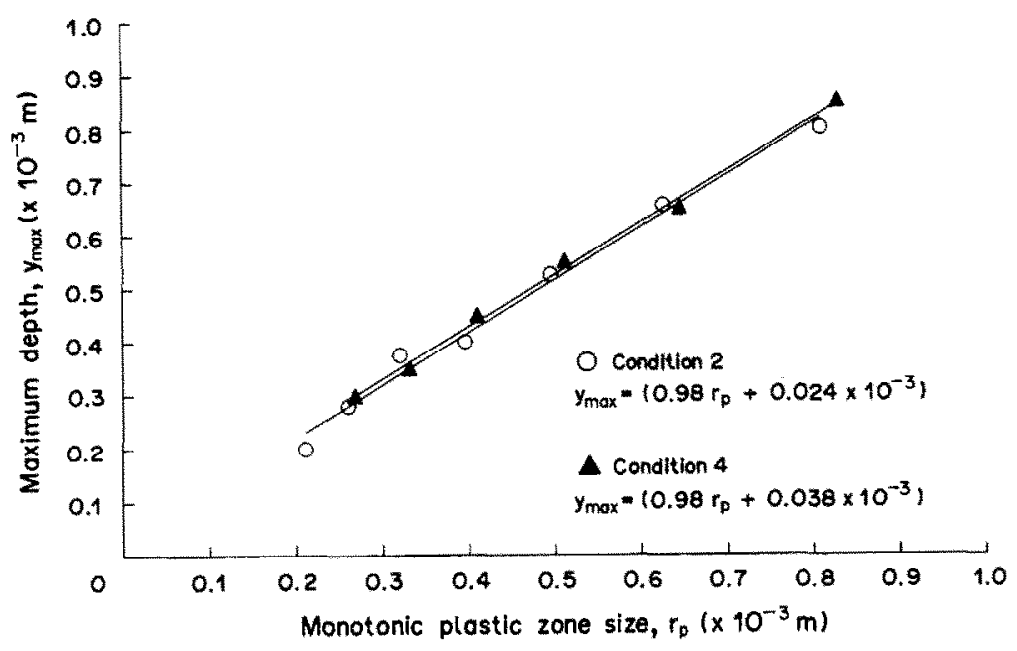

Fig. 7. Relation between $y_{\max }$ and monotonic plastic zone size $r_{p}$.

in magnitude is designated as $y_{\text {peak }}$ while the (larger) depth at which it reaches a minimum value (equivalent to that of base material) is designated as $y_{\max }$. The monotonic plastic zone size, $r_{\mathrm{p}}$, for different $K_{\max }$ values was calculated from the relation[21],

$$
r_{\mathrm{p}}=\frac{1}{2 \pi}\left\{\frac{K_{\max }}{\sigma_{\mathrm{ys}}}\right\}^{2}
$$

where $\sigma_{y s}$ is the yield stress of the material (Table 2). The relation between $y_{\max }$ and $r_{\mathrm{p}}$ for different $K_{\max }$ values is shown in Fig. 7 for conditions 2 and 4 . These results indicate a good correlation between the measured $y_{\max }$ and the calculated $r_{\mathrm{p}}$ values for both material conditions.

At all $K_{\max }$ levels, the differences between the residual stress at $y_{\text {peak }}$ position and the corresponding value at the fracture surface were found to be nearly constant and hence independent of $K_{\max }$ for a given material condition (inserts of Figs 5 and 6). On an average, this difference was found to be about $100 \mathrm{MPa}$ for condition 2 and about $30 \mathrm{MPa}$ for condition 4 . However, the $y_{\text {peak }}$ depths themselves were found to be different for different $K_{\max }$ levels exhibiting a linear relation. Figure 8 shows such a relationship for conditions 2 and 4 .

The corresponding variations of $B$ with depth for conditions 2 and 4 are shown in Figs 9 and 10. A decrease in $B$ was noticed up to depths $y_{\text {peak }}$ at which maxima in $\sigma_{\mathrm{r}}$ were observed (see inserts of Figs 9 and 10). At depths beyond $y_{\text {peak }}$, up to few tenths of a millimetre they show an increasing

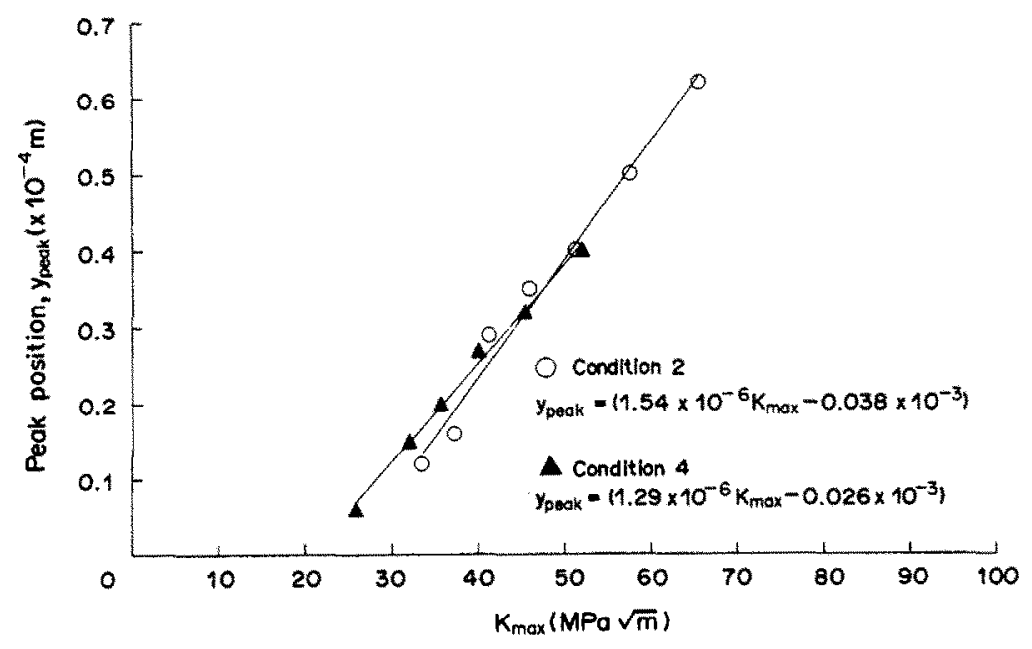

Fig. 8. Relation between $y_{\text {peak }}$ and $K_{\text {tnax }}$. 


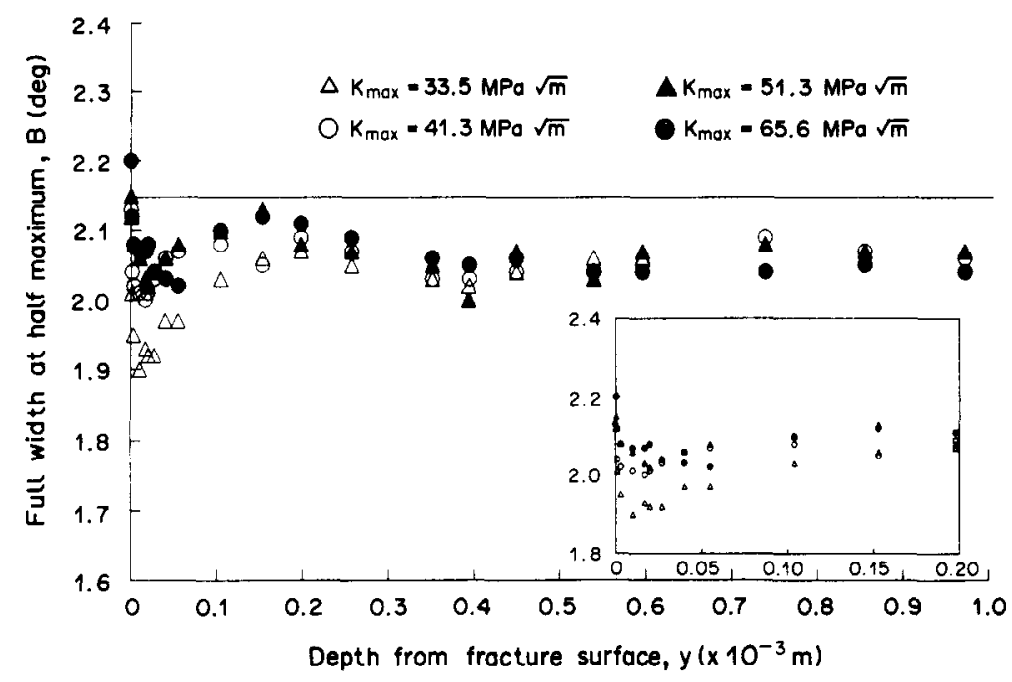

Fig. 9. Full width at half maximum, $B$, distribution below the fracture surface of specimen in condition 2 (WQ \& $200^{\circ} \mathrm{C}$ temper).

trend. Although in principle the plastic zone size can also be determined through measurements of $B$ practical difficulties were encountered in the exact evaluation of $y_{\max }$ (at which $B$ reached that of the base material value). Therefore, the results quoted in this work (Fig. 7) are only from $\sigma_{\mathrm{r}}-y$ determinations. On an average, $B$ values at $y_{\text {peak }}$ (denoted by $B_{\text {peak }}$ ) were found to be about 0.93 and 0.90 times the value at the fracture surface for conditions 2 and 4 respectively. The variation of $\left(B_{s} / B_{0}\right)$ and $\left(B_{\text {peak }} / B_{0}\right)$ with $K_{\max }$ is shown in Fig. 11. Here $B_{\mathrm{s}}$ refers to the value of $B$ at the fracture surface, $B_{\text {peak }}$ to that at the $y_{\text {peak }}$ and $B_{0}$ to that of the base material. $B_{0}$ was found to be $2.15^{\circ}$ and $1.85^{\circ}$ in conditions 2 and 4 . These observations indicate that the material might, in both conditions, have undergone an initial softening within this region.

Relationships between $y_{\text {peak }}$ at any $K_{\max }$ value and other parameters like reverse plastic zone size $\left(r_{\mathrm{pc}}\right)$, crack tip opening displacement $(\mathrm{CTOD}-\delta)$ and fracture process zone $(\mathrm{FPZ}-\chi)$ have also been examined. These parameters were determined using the following relations:

Reverse plastic zone,

$$
r_{\mathrm{pc}}=\frac{1}{2 \pi}\left\{\frac{\Delta K}{\sigma_{\mathrm{ys}}^{\prime}}\right\}^{2}
$$

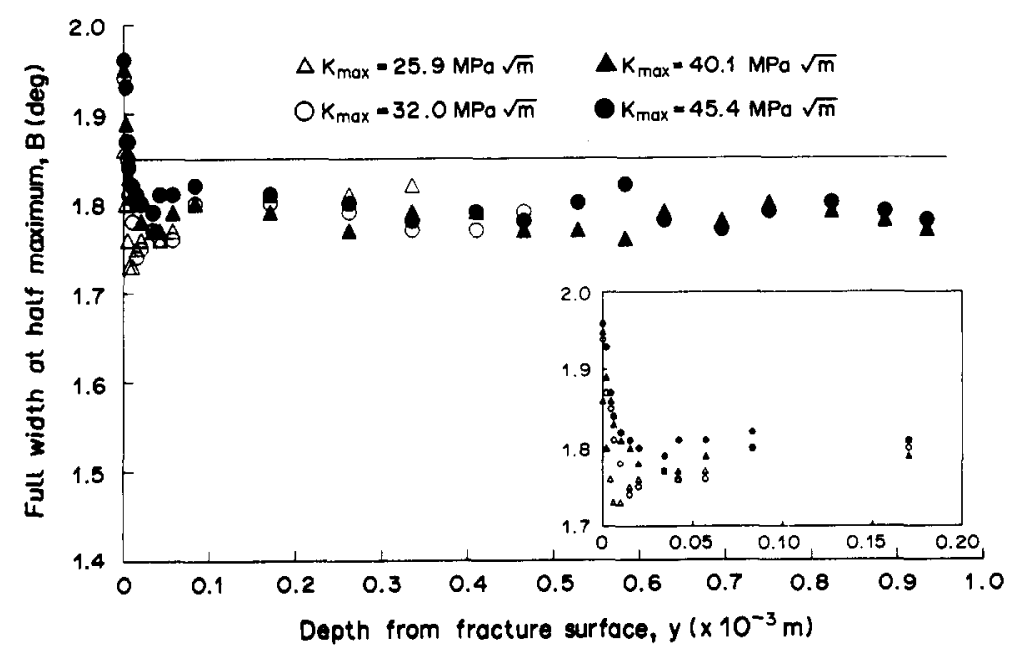

Fig. 10. Full width at half maximum $B$ distribution below the fracture surface of specimen in condition 4 (WQ \& $600^{\circ} \mathrm{C}$ temper). 
CTOD,

$$
\delta=\frac{K_{\max }^{2}}{E \sigma_{\mathrm{ys}}}
$$

FPZ,

$$
\chi=\frac{K_{\max }^{2}}{E \sigma_{\mathrm{ys}}}\left\{1-\left(1-\frac{K_{\min }}{K_{\max }}\right)^{2}\right\}^{0.5}
$$

where $E$ is the Young's modulus, $\sigma_{y s}$ is the yield stress, $\sigma_{y s}^{\prime}$ is the cyclic yield stress (assumed to be twice the monotonic yield stress in the present studies), $K_{\min }$ and $K_{\max }$ are the minimum and maximum stress intensity factors, respectively.

It is interesting to note that $y_{\text {peak }}$ exhibits a reasonably linear relationship with $K_{\max }$ (Fig. 8) as well as with each of the above parameters which in turn are proportional to $K_{\max }^{2}$. Perhaps the differences in yield properties and the cyclic response of the material in the regions close to crack tip, as a consequence of severe plastic strain cycling and the attendant local heating effects could be a reason for this.

Several investigators have made attempts to analyse the fatigue crack growth mechanisms through damage accumulation and low cycle fatigue[23, 24] concepts. According to these concepts, the near-tip regions of a growing crack are assumed to be comprised of small uniaxial fatigue elements subjected to non-proportional strain fields. Each such fatigue element will be in an elastic situation till it crosses the plastic zone boundary. Within the reverse plastic zone region, the element will be subjected to increasing plastic strain amplitudes as it moves towards the crack tip. Due to this plastic strain cycling, the element will undergo a certain amount of damage in each cycle. Final failure of the element can occur when the accumulated damage reaches a critical value[23]. In other words, the element may be expected to fail in the next immediate cycle when it approaches the crack tip by a critical distance which appears to be a material-dependent parameter. It was shown that fracture initiation at blunting prefatigued crack tip in a 4340 steel specimen (fracture toughness) involves initiation of voids within regions up to 1 to 2 times the CTOD and their coalescence with the crack tip through the intensely deformed ligaments[25]. In this case the fractures were reported to be mostly fibrous and were characterized by equiaxed dimples. In the present investigation the fracture morphology of the matcrial in condition 2 was found to be clcavage with the presence of localized dimples elongated in the direction of crack growth. In condition 4 , it was found to be of a mixed mode with about $30 \%$ fibrous content. The variation of $y_{\text {peak }}$ values with CTOD in conditions 2 and 4 are shown in Fig. 12. In these cases, the $y_{\text {peak }}$ values were found to be about 2.68 and 2.00 times the CTOD respectively. From these observations it appears that $y_{\text {peak }}$ may conform to the zone up to twice that of CTOD for fibrous fracture (condition 4 , for example)

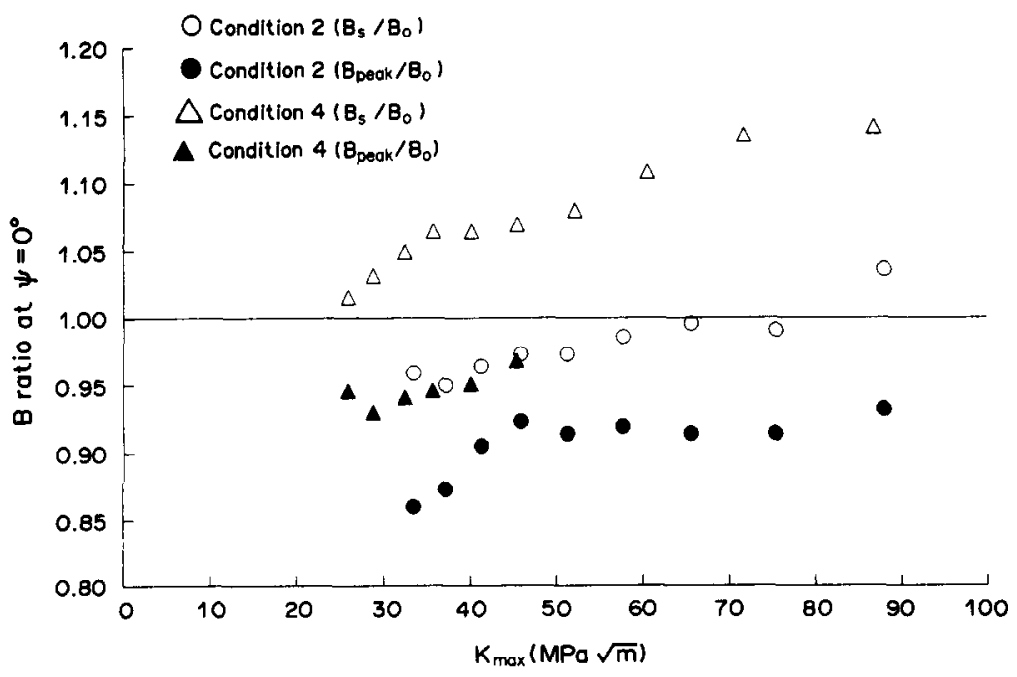

Fig. 11. Relation between $B$ ratio and $K_{\max }$. 


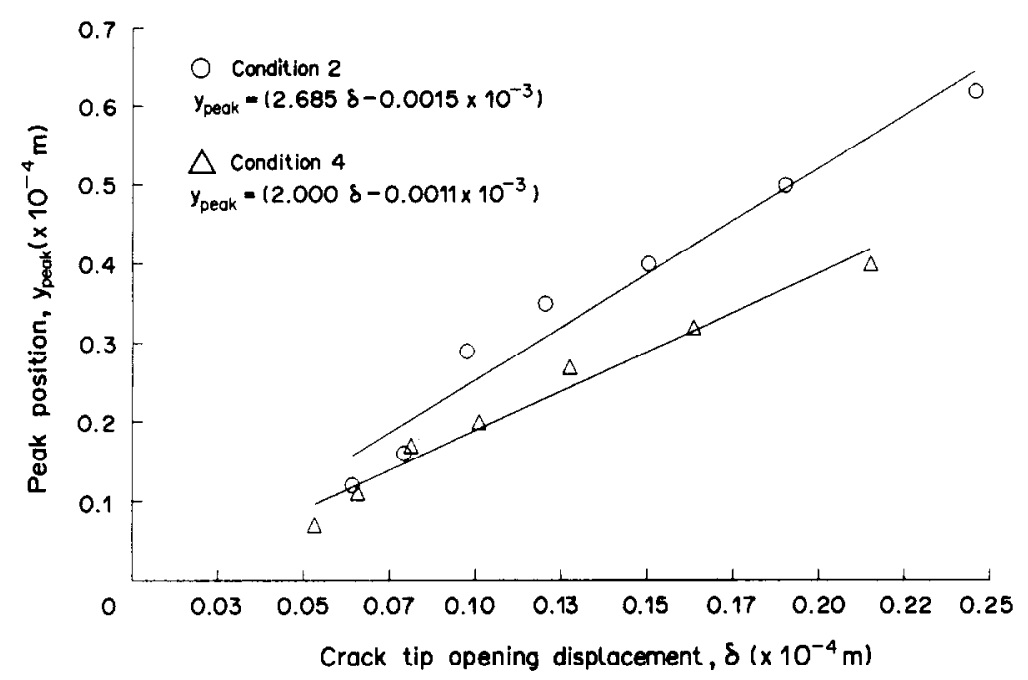

Fig. 12. Relation between $y_{\text {peak }}$ and crack tip opening displacement, $\delta$.

and to a larger zone greater than 2 times the CTOD for brittle fracture (condition 2). Thus an assumption that $y_{\text {peak }}$ may correspond to the near tip region in which the majority of the material damage occurs appears to be reasonable. Further investigations relating the influence of crack blunting, void coalescence and the associated temperature rise effects to the residual stress states at and below the fracture surface in the near crack tip regions may provide additional results and help in understanding the mechanisms.

\section{CONCLUSIONS}

The residual stress $\sigma_{\mathrm{r}}$ distributions on the fracture surface of $\mathrm{C} 45$ steel in different heat treated conditions were found to exhibit an increase followed by a decrease with increasing $K_{\max }$ values while the $B$ showed a monotonic increase.

Through single line profile (Voigt) analysis and observations made in the present work, it was noticed that between the microstrain and coherent domain size it was the former which plays a predominant role in line broadening.

A good correlation was found between the plastic zone size determined from the depth at which the residual stresses reach the base material value and the calculated monotonic plastic zone size.

The sub-surface measurements in conditions 2 and 4 indicated an increase in residual stress just below the fracture surface. The increase in residual stress was found to be about $100 \mathrm{MPa}$ and $30 \mathrm{MPa}$ in conditions 2 and 4 respectively. For a given material condition, this increase was found to be independent of $K_{\max }$.

The depths at which peaks occur at different $K_{\max }$ levels in $\sigma_{\mathrm{r}}-y$ plots were found to exhibit a linear relationship to the $K_{\max }$ and CTOD parameters. Such simultaneous linear dependence is assumed to be due to the differences in the yield and cyclic response characteristics of the material in the near tip region to severe plastic strain cycling and the attendant local heating.

The $y_{\text {peak }}-$ CTOD relationships indicated slopes of 2.68 and 2.00 for conditions 2 and 4 respectively. This observation seems to suggest that $y_{\text {peak }}$ may correspond to the near tip region in which the material undergoes fatigue damage due to plastic strain cycling (low cycle fatigue behaviour).

The $B-y$ relationships indicated minimum full width at half maximum values at $y_{\text {peak }}$ depths. This suggests that the material may have undergone a softening within the depths upto $y_{\text {peak }}$ in both conditions 2 and 4. 


\section{REFERENCES}

[1] Z. Yajima, Y. Hirose and K. Tanaka, X-ray diffraction observation of fracture surfaces of ductile cast iron. Adv. X-ray Anal. 26, 291-298 (1983).

[2] T. Mishima, Y. Nandyama, Y. Hirose and K. Tanaka, X-Ray fractography of fracture surface of alumina ceramics. Adv. X-ray Anal. 30, 545-55I (1986).

[3] Y. Hirose, Z. Yajima and K. Tanaka, X-Ray fractography on stress corrosion cracking of high strength steel. Adv. X-ray Anal. 27, 213-220 (1984).

[4] K. Tanaka and N. Hatanaka, Residual stresses near fatigue fracture surfaces of high strength and mild steels measured by X-ray method. J. Soc. Mater. Sci. (Japan) 31, 215-220 (1982).

[5] Y. Hirose and K. Tanaka, X-Ray measurements of residual stress near fatigue fracture surfaces of high strength steel. J. Soc. Mat. Sci. (Japan) 31, 265-270 (1982).

[6] K. Ogura, Y. Miyoshi and M. Kayama, A study of X-Ray analysis of fatigue fracture surface. Engng Fracture Mech. 22, 123-133 (1985).

[7] J. L. Lebrun, M. Barral, A. Bignonnet, C. M. Salin and A. Nhari, X-Ray fractography: A new technique for crack growth and failure analysis. Proc. Conf. Residual Stresses Sci. Technol., Garmisch-Partenkirchen (FRG), Vol. 1, pp. 109-116 (1986).

[8] S. Bayard and J. L. Lebrun, Application of X-Ray fractography to a cracked steam turbine shaft. Proc. Conf. Residual Stresses Sci. Technol, Garmisch-Partenkirchen (FRG), Vol. 2, pp. 935-942 (1986).

[9] K. Matsui, Y. Hirose, A. Chadani and K. Tanaka, X-Ray fractographic study on fracture of a machine part. Proc. Conf. ICRS-2, Nancy, (France), pp. 833-838 (1988).

[10] A. Komine, E. Nakanishi and K. Komine, Residual stresses at fatigue fracture surface of heat treated high strength steels. J. Soc. Mater. Sci. (Japan) 27, 245-250 (1978).

[11] Y. Kurebayashi, S. Kodama and H. Misawa, X-Ray fractography on $\Delta K$ constant fatigue fractured surface. J. Soc. Mater. Sci. (Japan) 31, 221-226 (1982).

[12] Y. Sekita, S. Kodama and K. Misawa, X-Ray fractography on fatigue fractured surface. J. Soc. Mater. Sci. (Japan) 32, 258-263 (1983).

[13] Y. Yoshioka, 17th Symp. Proc. on X-Ray study on deformation and fracture of a solid. J. Soc. Mater. Sci. (Japan), $20-25(1980)$.

[14] H. Muir, B. L. Averbach and M. Cohen, The elastic limit and yield behaviour of hardened steels. Trans. Am. Soc. Metals 47, 380-399 (1955).

[15] E. Macherauch and P. Muller, Das $\operatorname{Sin}^{2} \psi$-Verfahren der röntgenorafixchen Spannungsmessung. Z. angew. Phys. 13, 305-312 (1961).

[16] H. Schneider and R. Vasudevan, Structural deformation of manganese substituted mullites: X-ray line broadening and lattice parameter studies. $N$. Jb. Miner. Mh. H.4, 165-178 (1989).

[17] R. Delhez, Th. H. de Keyser and E. J. Mittemeijer, Determination of crystallite size and lattice distortions through $X$-ray diffraction line profile analysis. Fresenius Z. Anal. Chem. 312, 1-16 (1982).

[18] Th. H. de Kcijscr, J. I. Longford, E. J. Mittemeijer and A. B. P. Vogels, Use of Voigt function in a single-line method for the analysis of X-ray diffraction line broadening. J. appl. Cryst. 15, 308-314 (1982).

[19] J. I. Longford, Accuracy in powder diffraction. NBS Special Publication 567, (Edited by S. Block and C. R. Hubbard), 255-269 (1980).

[20] R. K. Gupta and T. R. Anantharaman, Shape analysis of X-ray diffraction broadening from deformed tungsten. Z. Metallkde 62, 732-735 (1971).

[21] A. Bignonnet, J. L. Lebrun and B. Guimard, Evaluation of the plastic zone size at the front of a fatigue crack by X-ray Fractography, in Proc. ECF 5, Lisbon, (Portugal) Vol. 2, pp. 843-853 (1984).

[22] B. Budiansky and J. W. Hutchinson, Analysis of closure in fatigue growth. J. appl. Mech. 45, 267-276 (1978).

[23] S. Majumdar and J. D. Morrow, Correlation between fatigue crack propagation and low cycle fatigue properties. ASTM STP 559, 159-182 (1974).

[24] Y. Birol, A low-cycle fatigue approach to fatigue crack propagation. Mat. Sci. 24, 1093-2098 (1989).

[25] S. Lee, L. Majno and R. J. Asaro, Correlation of microstructure and fracture toughness in two 4340 steels. Met. Trans. 16A, 1633-1648 (1985). 